\title{
Repeatability Tests of a Fire Risk Index Method for Multi-storey Apartment Buildings
}

\author{
BJÖRN KARLSSON ${ }^{1}$, and BÖĐVAR TÓMASSON ${ }^{2}$ \\ ${ }^{1}$ Iceland Fire Authority \\ Skulagata 21 \\ Reykjavik, Iceland \\ ${ }^{2}$ Línuhönnun Consulting Engineers \\ Reykjavik, Iceland
}

\begin{abstract}
Due to advances in building regulations, many timber frame multi-storey apartment buildings have been constructed in the Nordic countries. However, until now, no comprehensive method to estimate fire risks in such buildings has been available to designers. This paper briefly outlines a methodology for developing risk index methods for this purpose and describes the development and testing of such a method, FRIMMAB. It shows how the method has been evaluated against a more complex quantitative risk analysis technique. It describes how a maximum allowable risk index value can be determined when using building codes in the Nordic countries (Sweden, Norway, Finland and Denmark). The paper shows how the method has been tested on 20 different multistorey apartment buildings. Finally, the paper describes how 5 different engineers used the same documentation to evaluate four different buildings, thus allowing a check of the repeatability of the method.
\end{abstract}

KEYWORDS: fire risk, index method, timber frame buildings, repeatability

\section{INTRODUCTION AND BACKGROUND}

In the last few years a number of multi-storey apartment buildings have been constructed in the Nordic countries using timber as load bearing material. Such constructions have earlier not been allowed by the authorities, mainly due to the fire risk. The Nordic countries have therefore co-operated for some years, within an organisation named Nordic Wood, with the aim of developing construction methodologies that seriously diminish the fire risk in timber-frame multi-storey buildings. As a part of this work, a Nordic handbook on fire safety design of timber buildings were published in 1999 and an extended version in 2002.

One reason why multi-storey timber frame buildings were not allowed in earlier building regulations was due to the fire risk. Authorities and industry found that it was necessary to develop a new fire risk assessment technique to verify that fire safety can be as high in timber-frame buildings as in other types of buildings, given that the right construction methods are used [1]. A research and development program called Nordic Wood therefore initiated work that led to the development of FRIM-MAB, a Fire Risk Index Method for Multi-storey Apartment Buildings.

The method, its development, its testing and its evolvement is described in a number of reports and papers available on the web-site www.brand.lth.se/frim-mab. The method was evaluated against a much more elaborate quantitative risk analysis (QRA) method. Both the index method and the quantitative risk analysis were used to rank four different buildings with respect to fire risk and the ranking was identical. 
Nordic Wood found it necessary to further test the method, where 20 timber frame buildings in four Nordic countries were analysed. This resulted in the determination of a limiting risk index value based on the minimum demands made in the building regulations for each Nordic country, thus establishing a certain benchmark for users of the index method.

Nordic Wood also found it necessary to investigate to some extent the repeatability of the method and this document reports on that work. Four multi-storey apartment buildings were chosen among the 20 buildings analysed in the earlier work. Drawings and fire documentation of these four buildings were sent to four different fire safety engineers who analysed the buildings according to the FRIM-MAB methodology. Their results were compared with each other, and with the analysis made in the earlier work, in order to test the repeatability of the risk index method. Therefore, five different engineers have analysed the same four buildings.

Earlier work has reported on the development of the method and it's evaluation against a more elaborate quantitative risk analysis (QRA) method. This paper focuses on describing a further test of the method where 20 buildings were analysed. It also shows how a limiting risk index value can be determined by using the minimum requirements given in building codes. Finally, the paper reports on a repeatability test of the method.

\section{General on the Index Method}

The word risk is used in many different contexts and has different meanings attached to it. The terms risk analysis; risk evaluation and risk assessment are used to describe different parts of the work that is performed to quantify risk [2]. There are mainly three types of such methods; Qualitative methods; Semi-quantitative methods and Quantitative methods.

The only risk assessment method that is simple to use and at the same time takes account of the many different objectives and parameters that constitute building fire safety is a semi-quantitative index method of the type that is presented here.

The level of fire safety for an object depends on many different factors; these factors are sometimes called components or attributes. The term Multi Attribute Decision Making (MADM) [3] has been used as a uniting name for techniques that allow decision makers to find the best combination of different attributes. Watts [4] described the use of multi attribute evaluation in fire safety and suggested a general five-step process when constructing a multi attribute model. Developing such a model requires that certain important criteria be fulfilled. Watts [5] also compiled a list of 10 fundamental criteria based on a review of existing risk ranking systems. Watts' [4,5] suggestions and criteria have been followed when developing the method described here.

The method was developed by a Nordic project group, using a so-called Delphi panel for fine-tuning the method. The Delphi panel was made up of 20 Nordic experts who work with fire safety in various areas. The development of the structure of this method has been described in detail by Larsson [6] and a detailed description of the Delphi panel work carried out within the project was described by Karlsson and Larsson [7]. A general description of the Delphi technique is given by Lindstone et al. [8]. Shields [9] also describes the technique, its advantages, limitations and the problems associated with the process, as well as giving an example of a practical application. 
The risk index method described in this paper was developed by a Project group, with one member from each of the Nordic countries. Suggestions for actions were formulated by the Project manager and sent to the Project group, who commented on the suggestions. The main purpose of the Project group was to prepare proposals for the Delphi group. The Project group met 3-4 times per year during the project duration. Figure 1 shows a schematic of how the work was conducted within the project.

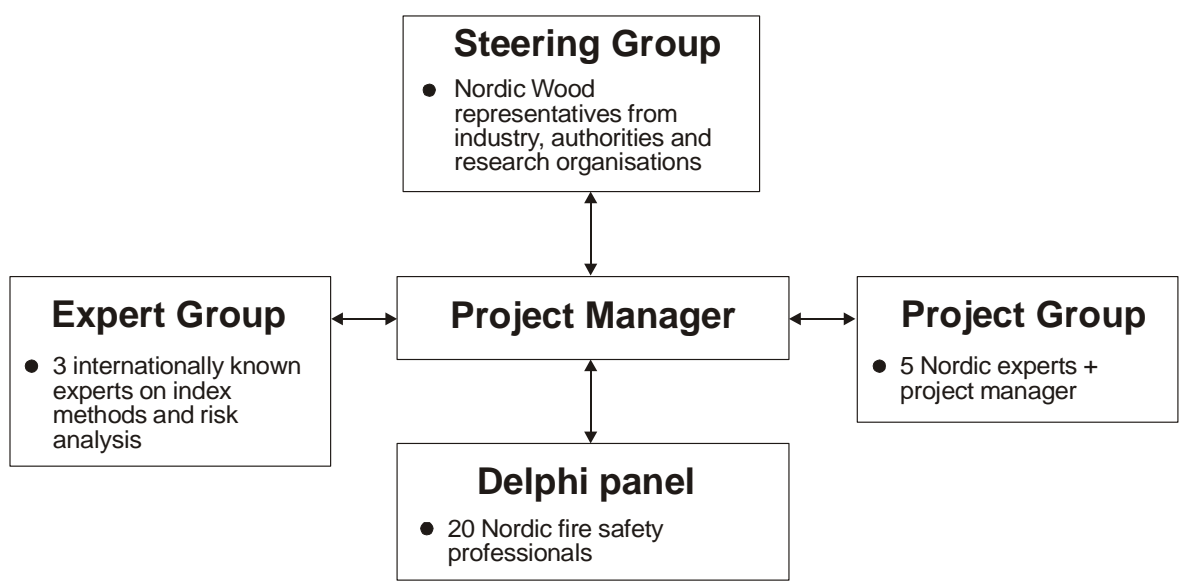

Fig. 1. A schematic of the project organization and flow of information.

The Fire Risk Index Method for Multi-storey Apartment Buildings (FRIM-MAB) is based on a hierarchical system. Each "decision making level" of the hierarchy is composed of different "attributes," i.e., components that account for an acceptably large portion of the total fire safety. The attributes of FIRM-MAB were derived using the wellestablished NFPA Fire Safety Concepts Tree [11].

The top level in the hierarchical system is the Policy (for example "the building must have acceptable fire safety"), then the Objectives are specified (for example "save lives" and "protect property"), the next level specifies the Strategies (for example "safe evacuation" and "passive fire safety") and finally a large number of Parameters are given (for example "suppression system," "load bearing capacity," and "fire brigade"). Figure 2 shows a simplified schematic of the policy, objectives and strategies, the full definitions are given by Karlsson [12].

\begin{tabular}{|c|c|}
\hline Policy & Acceptable fire safety level, multi-storey apartment buildings \\
\hline \multirow[t]{2}{*}{ Objectives } & $\mathrm{O}_{1}$ Save lives \\
\hline & $\mathrm{O}_{2}$ Protect property \\
\hline \multirow[t]{4}{*}{ Strategies } & $P_{1}$ Active fire safety to limit fire growth \\
\hline & $\mathrm{P}_{2}$ Passive fire safety \\
\hline & $P_{3}$ Safe evacuation \\
\hline & $\mathrm{P}_{4}$ Safe rescue operation \\
\hline Parameters & $P_{1}-P_{17}$ (See Table 1$)$ \\
\hline
\end{tabular}

Fig. 2. A simplified schematic of the policy, objectives and strategies, full definitions given by Karlsson [12]. 
A list of the 17 parameters is given in Table 1. The Parameters can then be divided into sub-parameters that are quantifiable, either directly or through the use of Decision Tables.

Table 1. A list of the 17 parameters, full definitions are given by Karlsson [12].

\begin{tabular}{|l|l|l|l|}
\hline \multirow{2}{*}{ Parameter } & \multicolumn{3}{|l|}{} \\
\hline P1 & Linings in apartment & P10 & Adjacent buildings \\
\hline P2 & Suppression system & P11 & Smoke control system \\
\hline P3 & Fire service & P12 & Detection system \\
\hline P4 & Compartmentation & P13 & Signal system \\
\hline P5 & Structure - separating & P14 & Escape routes \\
\hline P6 & Doors & P15 & Structure - load-bearing \\
\hline P7 & Windows & P16 & Maintenance and information \\
\hline P8 & Facade & P17 & Ventilation system \\
\hline P9 & Attic & & \\
\hline
\end{tabular}

Subsequently, each parameter is described, sometimes using sub-parameters and decision tables. Figure 3 shows a fictive example of how decision tables and sub-parameters can be used to arrive at a numerical score or grade for a given parameter. The user then works through each parameter until all parameters have been given a grade. Finally, the grades are entered in a table and multiplied by weights. A Delphi panel process is used to determine the weight of each parameter. These weighted grades are then summed up and result in a single index value for the building in question.

The Fire Risk Index Method for Multi-storey Apartment Buildings (FRIM-MAB) can be downloaded from the website http/www.brand.lth.se/frim-mab. The main document, Karlsson [12], consists of tables and grading schemes to allow an index to be calculated. The document is also available in a format that allows the values to be entered digitally on a computer, so that the index is calculated automatically for each case that is analyzed, eliminating all hand calculations. Several other background documents can be downloaded from the same website $[6,7,10]$. 


\section{$\mathbf{P}_{2}$. SUPPRESSION SYSTEM \\ DEFINITION: Equipment and systems for suppression of fires}

\section{SUB-PARAMETER $\mathbf{P}_{2 a}$, Automatic sprinkler system}

Type of sprinkler ( $\mathrm{N}=$ no sprinkler, $\mathrm{A}=$ apartment sprinkler, $\mathrm{O}=$ ordinary sprinkler) and Location of sprinkler $(\mathrm{A}=$ in apartment, $\mathrm{E}=$ in escape route, $\mathrm{B}=$ both in apartment and escape route)

\begin{tabular}{|c|c|c|c|c|c|c|c||}
\hline \multicolumn{1}{|c||}{ SURVEY ITEMS } & \multicolumn{6}{|c|}{ DECISION RULES } \\
\hline \hline Type of sprinkler & N & A & A & A & O & O & O \\
\hline Location of sprinkler & - & A & E & B & A & E & B \\
\hline \hline GRADE & N & M & L & H & M & L & H \\
\hline
\end{tabular}

( $\mathrm{N}=$ no grade, $\mathrm{L}=$ low grade, $\mathrm{M}=$ medium grade and $\mathrm{H}=$ high grade)

\section{SUB-PARAMETER $P_{2 b}$, Portable equipment}

\begin{tabular}{|c|l|}
\hline $\mathrm{N}$ & None \\
\hline $\mathrm{F}$ & Extinguishing equipment on every floor \\
\hline $\mathrm{A}$ & Extinguishing equipment in every apartment \\
\hline
\end{tabular}

RESULTING PARAMETER GRADE:

\begin{tabular}{|c||c|c|c|c|c|c|c|c|c|c|c|c||}
\hline \multicolumn{1}{|c||}{ SUB-PARAMETERS } & \multicolumn{10}{|c||}{ DECISION RULES } \\
\hline \hline Automatic sprinkler system & N & N & N & L & L & L & M & M & M & H & H & H \\
\hline Portable equipment & N & F & A & N & F & A & N & F & A & N & F & A \\
\hline \hline GRADE & $\mathbf{0}$ & $\mathbf{1}$ & $\mathbf{1}$ & $\mathbf{2}$ & $\mathbf{2}$ & $\mathbf{2}$ & $\mathbf{3}$ & $\mathbf{3}$ & $\mathbf{4}$ & $\mathbf{4}$ & $\mathbf{5}$ & $\mathbf{5}$ \\
\hline
\end{tabular}

(Minimum grade $=0$ and maximum grade $=5$ )

Fig. 3. A fictive example of how parameters are graded using survey items, sub-parameters and decision tables.

\section{EVALUATION, COMPARISON WITH A STANDARD QRA METHOD}

In order to get some idea of the validity of the Fire Risk Index Method, work was carried out with the aim to compare it against accepted fire design methods. However, for very many of the factors that constitute fire safety in a timber frame building, there are no accepted fire design methods available. For example, firestops at joints, intersections and concealed spaces are very important in timber-frame buildings, but there is no method available to calculate or numerically compare different design solutions in this respect. The evaluation can therefore only result in some indications on validity and is to a considerable extent based on subjective judgment.

A standard quantitative risk analysis (QRA) based on an event tree was used as a comparative methodology. This is a very useful technique to identify the outcome of a fire as well as to illustrate the sequence of events involved in ignition, fire development, fire control, evacuation, etc. But since there is a lack of deterministic design methods for many of the attributes considered in the index method, the QRA mainly concentrated on evacuation safety. Figure 4 shows an example of a simple event tree for a fire, used as a base for a QRA.

The risk for each sub-scenario is calculated by multiplying the probability of the subscenario by its consequence. The total risk is the sum of the risks for all sub-scenarios in the event tree. 


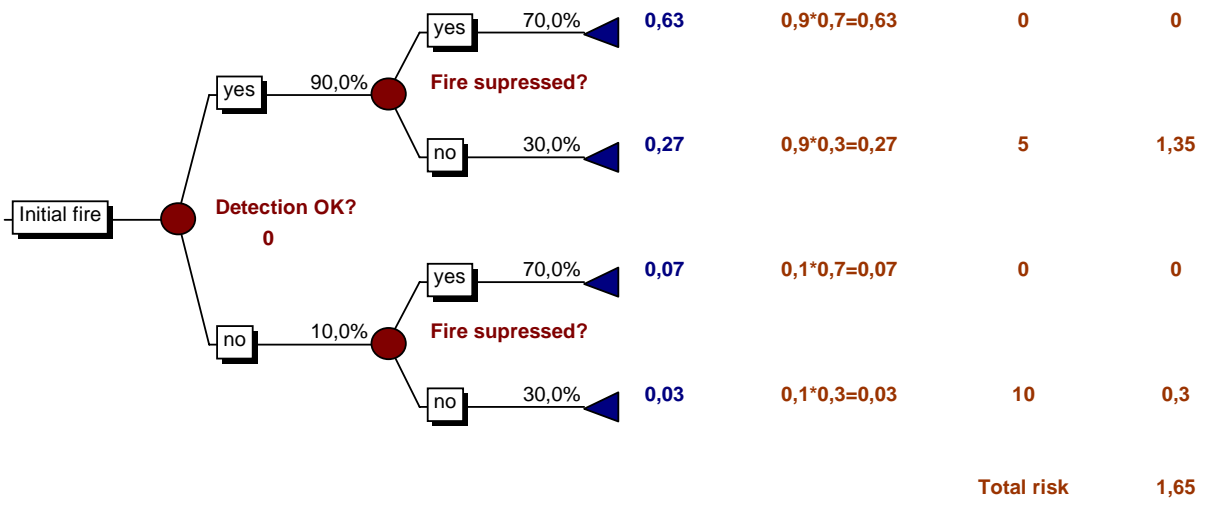

Fig. 4. A simplified example of an event tree for a fire.

If a definitive measure of the risk is to be produced every combination of fire source, target location and fire scenario has to be considered. However, the amount of computational effort required increases rapidly with the number of sources, scenarios and targets considered. Therefore some limitations and assumptions have to be made to simplify the problem. Performing a qualitative design review, QDR [13], can help limit the problem. In short, the objective of the QDR is to review the architectural design, identify fire hazards and possible consequences and specify fire scenarios for the quantitative analysis.

Four buildings were analysed in a number of ways. The resulting event trees for each of these buildings are too complex to be reproduced here, but they are given by Hultquist and Karlsson [10]. Some of the events that were considered in these trees were initial fire location, flaming or glowing fire, automatic fire detection, occupant suppression, sprinkler failure, open or closed doors, location of occupants, flashover, façade fire spread and occupant condition (awake or sleeping). Probabilities for each of these events were considered.

The analysis resulted in two rankings of the buildings, one from FRIM-MAB and one from the standard QRA. These rankings were compared and conclusions were drawn on how well FRIM-MAB operated.

The QRA was carried out on four buildings in the Nordic countries, one in Sweden (Wälludden), one in Norway (Einmoen), one in Denmark (Casa Nova) and one in Finland (Viikki). Separately, but at the same time, four independent consultant engineers analysed the same four buildings using the FRIM-MAB index method.

The QRA does not take account of property protection but mainly considers life safety, while the index method takes account of both objectives. Therefore, FRIM-MAB was used to calculate two different indices; the ordinary Risk Index (taking account of both life safety and property protection) and; an Occupant Escape Index (where only life safety is considered).

The QRA resulted in a certain ranking of the four buildings based on fire risk. Figure 5 shows how the risk ranking from the QRA method results in the exact same ranking as both the ordinary Risk Index and the Occupant Escape Risk Index. Note that the two 
scales in the diagram (Expected Risk and Risk Index) are not comparable numerically; the numbers can only be used to show how the methods rank the different buildings.

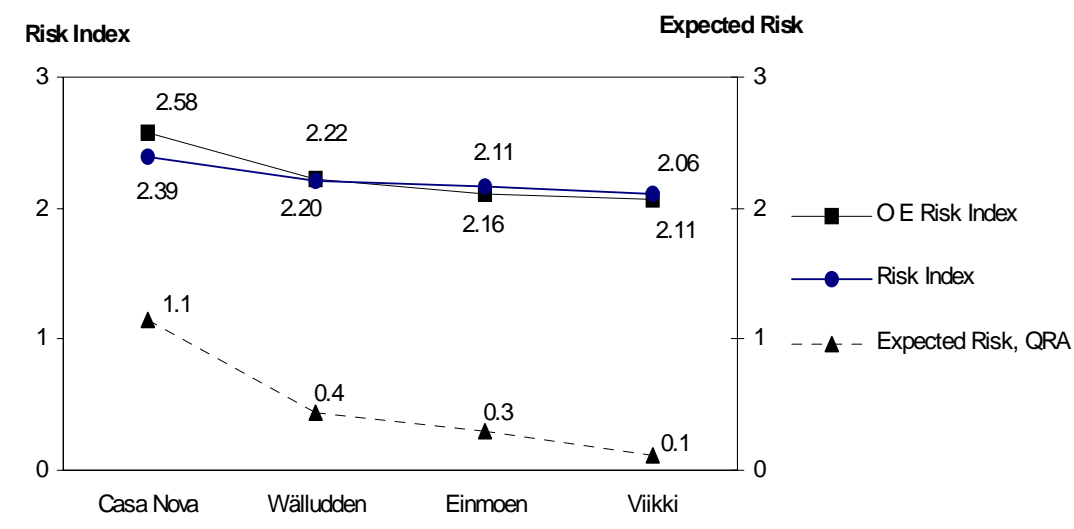

Fig. 5. The two risk indicies arrived at using FRIM-MAB (the ordinary Risk Index and the Occupant Escape Risk Index) rank the 4 buildings

in the same order as the QRA method.

It should be carefully noted that the QRA methodology and the Risk Index methodology are very different with respect to the assumptions made along the way. Note that the measuring units for the two methods are quite different and not comparable, but the ranking is. When using the QRA methodology, very rough assumptions must be made regarding the course of events, human behaviour and the fire induced environment. Similarly, there are extreme simplifications embedded in the Risk Index method, but these simplifications are of a different nature than the assumptions made in the QRA method.

It must therefore be seen as a very good sign that these very different methods rank the 4 buildings the same with regards to fire risk. Due to the complexity of the phenomena that the QRA and the Risk Index method try to address, it is impossible to directly validate either methodology against experiments. Nevertheless, the results presented above must be considered to have shown some degree of validation.

\section{Testing the Method and Determining a Limiting Risk Index Value}

Although the QRA comparison had to some extent given credibility to the fire risk index method, Nordic Wood found it necessary to further test the method. Therefore, 20 timber frame buildings in four Nordic countries were analysed. Also, the building codes of the four Nordic countries were investigated in order to determine a limiting risk index value based on the minimum demands made in the building regulations for each Nordic country, thus establishing a certain benchmark for users of the index method.

Results for Sweden, Norway, Finland and Denmark are given in the full report. As an example of this work, the Swedish Building Code divides buildings into three classes, BR1, BR2 and BR3 where the highest demands on safety are made for a BR1 building. A BR1 building has three or more storeys, or is a two storey building used as a hotel or for a similar purpose. A BR2 building has two storeys with a floor area greater than $200 \mathrm{~m}^{2}$ 
and more than two apartments. And finally, BR3 buildings are all but BR1 and BR2 buildings.

The minimum requirements in the Swedish Building Code, for these three types of buildings were analysed with regards to the 17 parameters given in Table 2. Thus, the limiting risk index value, based on the minimum demands in the Swedish Building Code, was determined for the BR1 and the BR2 building types. The results showed that the highest risk index value for a BR1 building, allowable by the Swedish Building Code, was 2.75 (the maximum attainable risk index value being 5). Similarly, the minimum risk index value for a BR2 building was 2.95.

The use of the index method was now tested on 15 Swedish multi-storey apartment buildings. The results are given in Fig. 6.

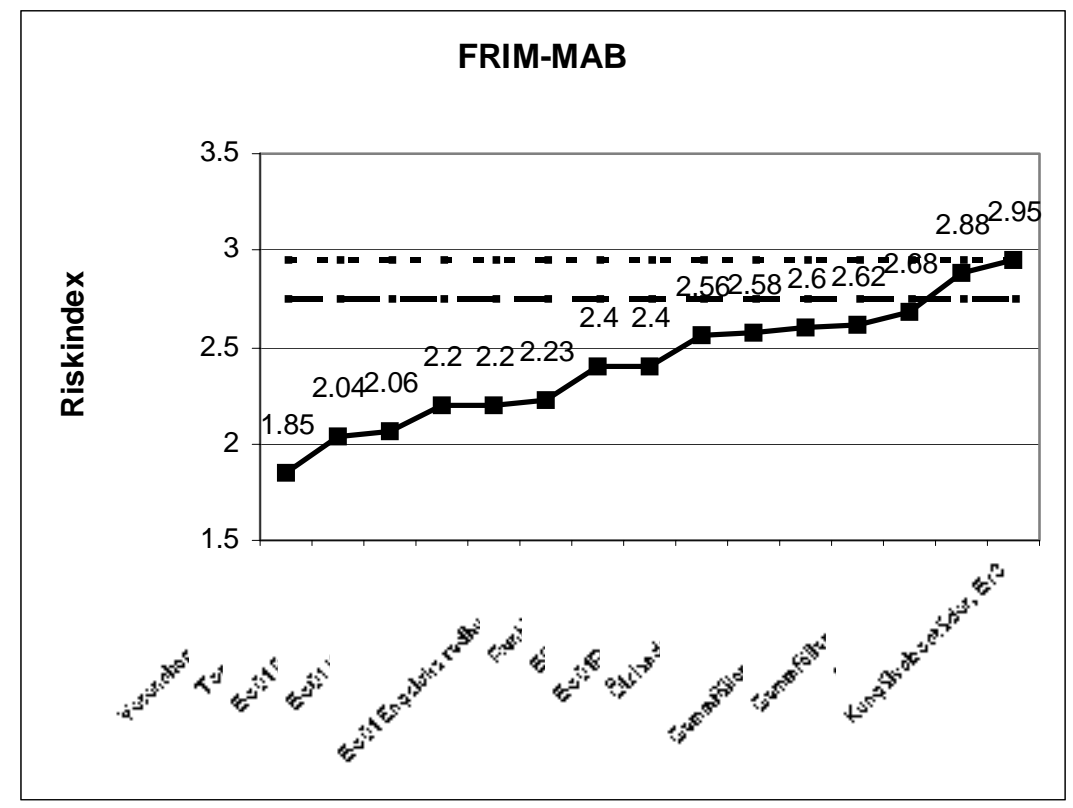

Fig. 6. Risk index value of 15 Swedish multi-storey apartment buildings that were analyzed by FRIM-MAB, and the two minimum risk index values allowed for building types BR1 and BR2 by the Swedish Building Code.

A number of other buildings were also analysed in a similar manner in Norway, Finland and Denmark. The full results are given by Christensson and Karlsson [14].

\section{Repeatability of the Fire Risk Index Method}

Four multi-storey apartment buildings were chosen among the 20 buildings analyzed in the work by Christensson and Karlsson [14]. Drawings and fire documentation of these four buildings were sent to four different fire safety engineers who analyzed the buildings according to the FRIM-MAB methodology. Their results were compared with each other, and the analysis made in the thesis work, in order to test the repeatability of the risk index method. Therefore, five different engineers have analysed the same four buildings, and the results are presented below. 
The four buildings chosen were called Vetenskapsstaden, Kanalhuset, Runhällen and Saghaugen Terrasse. The five engineers who did the evaluation had exactly the same information to do their analysis. Figures 7, 8, 9, and 10 show how the five engineers gave ratings to the 17 parameters for the four abovementioned buildings.

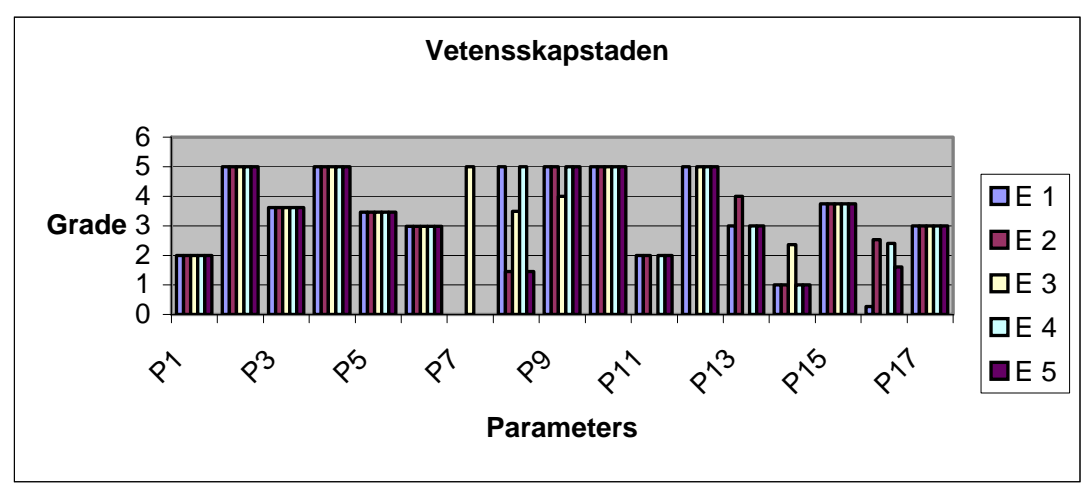

Fig. 7. The 17 parameters as valued independently by 5 engineers for the Vetenskapsstaden building.

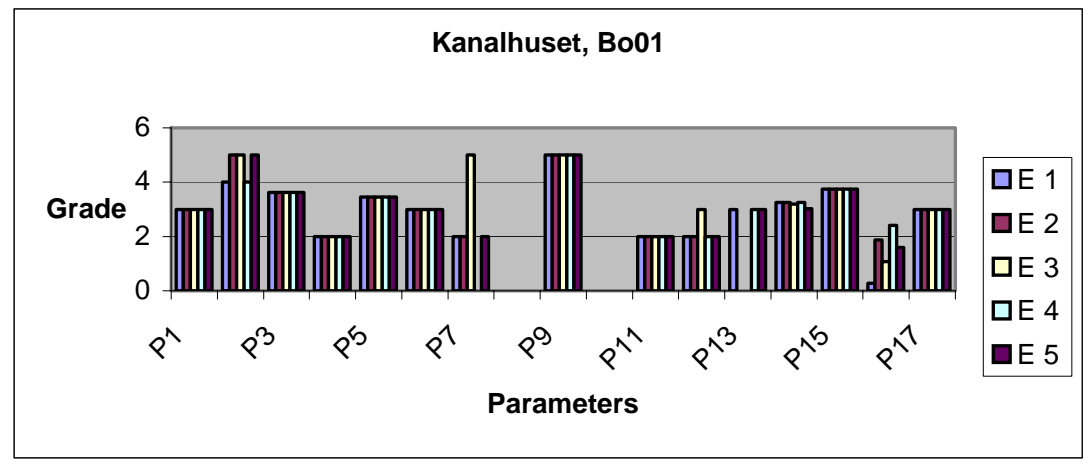

Fig. 8 . The 17 parameters as valued independently by 5 engineers for the Kanalhuset building.

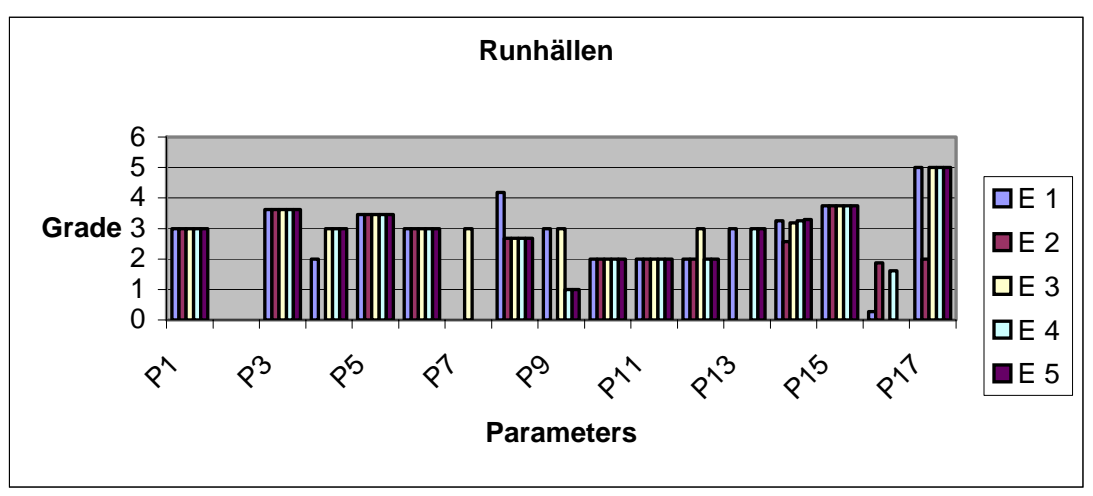

Fig. 9. The 17 parameters as valued independently by 5 engineers for the Runhällen building. 


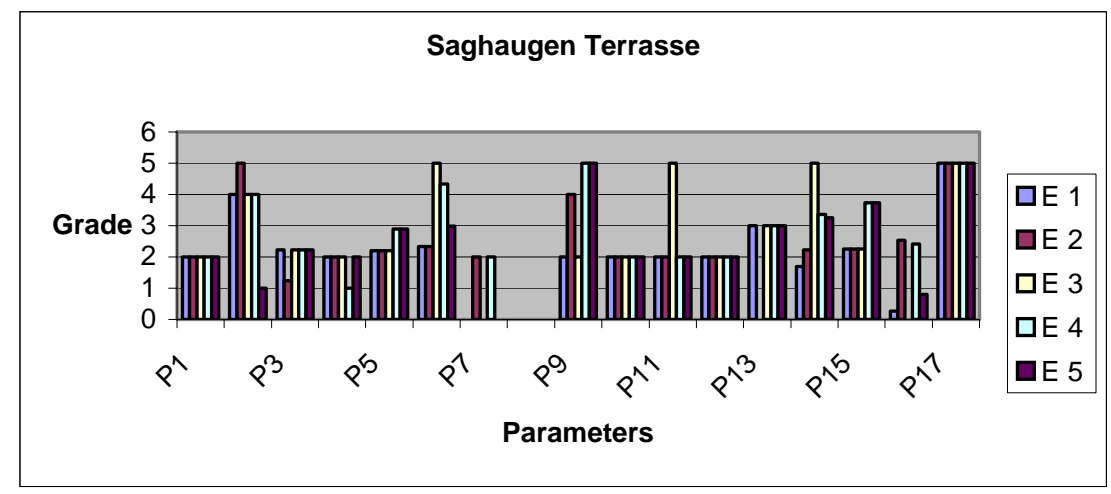

Fig. 10. The 17 parameters as valued independently by 5 engineers for the Saghaugen Terrasse building.

\section{CONCLUSIONS AND RECOMMENDATIONS FOR FUTURE WORK}

Due to advances in building regulations, many timber frame multi-storey apartment buildings have been constructed in the Nordic countries. However, until now, no comprehensive method to estimate fire risks in such buildings has been available to designers. This paper has

1. briefly outlined a methodology for developing risk index methods for this purpose

2. described the development and testing of such a method, FRIM-MAB, following a rigorous methodology, using a Delphi panel and several experts

3. evaluated the method against a more complex quantitative risk analysis technique

4. determined the maximum allowable risk index value when using building codes in the Nordic countries (Sweden, Norway, Finland and Denmark)

5. tested the method on 20 different multi-storey apartment buildings

6. tested the repeatability of the method by asking 5 different engineers to use the same documentation to evaluate four different building and checking how they gave grades to 17 different parameters.

To evaluate the index method, a quantitative risk analysis (QRA) was carried out on four multi-storey timber-frame buildings, recently constructed in four Nordic countries. Both the index method and the quantitative risk analysis were used to rank the buildings with respect to fire risk. The comparison showed a reasonably good agreement, keeping in mind that the two methods are very different in nature. Hultquist and Karlsson [10] describe the comparison in detail.

The advantage of using an index method for fire risk ranking is that the ranking takes little time and can be carried out by an engineer or a fire safety professional. All other rational methods for this purpose would take much longer time and must be carried out by specialists in fire safety design and risk analysis.

The FRIM-MAB method can be divided into 17 different parameters, $\mathrm{P}_{1}-\mathrm{P}_{17}$, where each parameter is given a grade. The five engineers therefore gave five grades for the same parameter, and they did this for four different buildings. The results show that the 
repeatability is excellent for most parameters and quite good for other parameters. The main result is that the overall repeatability is very good.

One important limitation of the method was, however, discovered, and this limitation has to do with buildings that have external walkways. One of the four analysed buildings had external walkways and the repeatability for that building was much poorer than for the other types of buildings.

In general, no engineering method has perfect repeatability. There is, for example, always a possibility for user error or differences in users' understanding of engineering methods. This is also true of FRIM-MAB and the results of this survey clearly show such errors. One way of diminishing such errors is to provide help-texts for the user.

To further improve the repeatability of the method, also with regards to buildings with external walkways, help-texts were written down for each parameter. These help-texts have been incorporated into the main document describing the method for users, hopefully leading to further improvements in repeatability.

Version 2.0 contains more comments from users than version 1.2 as a result of further analysis and applications to more buildings.

We conclude that the Fire Risk Index method presented has considerable promise, but since only 4 buildings were evaluated against a different methodology, it is clear that further work is needed to assess the method and to make adjustments to it. It has been suggested that several independent engineers and designers should test the method on a large number of buildings, in order to test repeatability and reproducibility of the results and to collect help-texts to assist the users. It has also been recommended that this type of work should be carried out on a European level.

The Fire Risk Index Method for Multi-storey Apartment Buildings (FRIM-MAB) can be downloaded from the website http/www.brand.lth.se/frim-mab. The main document, Karlsson [12], consists of tables and grading schemes to allow an index to be calculated. The document is also available in a format that allows the values to be entered digitally on a computer, so that the index is calculated automatically for each case that is analysed, eliminating all hand calculations. Several other background documents can be downloaded from the same website $[6,7,10]$.

\section{REFERENCES}

[1] Magnusson, S.E., and Rantatalo, T., "Risk Assessment of Timberframe Multistory Apartment Buildings - Proposal for a Comprehensive Fire Safety Evaluation Procedure,” Report 7004, Department of Fire Safety Engineering, Lund University, Lund, Sweden, 1998.

[2] Watts, J.M. Jr., "Fire Risk Ranking, Section 5," Chapter 2, SFPE Handbook of Fire Protection Engineering, 2nd Edition, USA, 1995.

[3] Yoon, K.P., and Hwang C.L., "Multiattribute Decision Making - An Introduction,” Sage Publications, USA, 1995.

[4] Watts, J.M. Jr., "Fire Risk Assessment Using Multiattribute Evaluation,” Fire Safety Science - 5th International Symposium, pp. 679-690, USA, 1997.

[5] Watts, J.M. Jr., “Criteria for Fire Risk Ranking,” Fire Safety Science Proceedings of the Second International Symposium, pp. 457-466, USA, 1991. 
[6] Larsson, D., "Developing the Structure of a Fire Risk Index Method for Multistorey Apartment Buildings,” Dept. of Fire Safety Eng., Lund University, Report 5062, Lund 2000.

[7] Karlsson, B., and Larsson D., "Using a Delphi Panel for Developing a Fire Risk Index Method for Multi-storey Apartment Buildings,” Report 3114, Department of Fire Safety Engineering, Lund University, Lund, Sweden, 2000.

[8] Linstone, H.A., and Turoff, M., "The Delphi Method - Techniques and Applications,” Addison-Wesley Publishing Company, 1975.

[9] Shields, T.J., "A Fire Safety Evaluation Points Scheme for Dwellings," University of Ulster at Jordanstown, Northen Ireland, 1991.

[10] Hultquist, H., and Karlsson, B., "Evaluation of a Fire Risk Index Method for Multi-storey Apartment Buildings,” Report 3088, Department of Fire Safety Engineering, Lund University, Lund, 2000.

[11] NFPA, NFPA 550, “Guide to the Fire Safety Concepts Tree 1995 Edition,” MA, USA, 1995.

[12] Karlsson, B., "Fire Risk Index Method for Multi-storey Apartment Buildings Report I0009025,” Trätek AB, Stockholm, 2000.

[13] BSI, Draft for Development DD240. "Fire Safety Engineering in Buildings, Part 1: Guide to the Application of Fire Safety Engineering Principles,” British Standards Institution, London, 1997.

[14] Christensson, A., and Karlsson, B., "Repeatability of FRIM-MAB Fire Risk Index Method for Multistory Appartment Buildings,” Report P0212052, Trätek AB, Stockholm, 2002. 